\title{
A DIMENSÃO FREIREANA NA EDUCAÇÃO PROFISSIONAL E TECNOLÓGICA: UM OLHAR SOBRE TESES E DISSERTAÇÕES
}

\section{GLADIS TERESINHA SLONSKI}

\author{
Instituto Federal de Educação, Ciência e Tecnologia de Santa Catarina \\ E-mail: glaslonski@yahoo.com.br
}

RESUMO:

Por acreditar que perspectiva educacional freireana está em sintonia com a concepção de educação emancipatória pretendida pelos documentos oficiais e diretrizes dos Institutos Federais, assim como na busca pelo desenvolvimento de abordagens teórico-metodológicas que estejam voltadas à efetivação desse objetivo, esta pesquisa busca compreender como a obra de Paulo Freire vem sendo utilizada no contexto da Educação Profissional e Tecnológica. Para tanto, foi realizada uma análise da produção acadêmica da área no Banco de Teses e Dissertações da CAPES. Foi possível evidenciar que os trabalhos que investigam o contexto da Educação Profissional e Tecnológica e que utilizam Paulo Freire como referencial teórico o fazem com coerência, defendendo uma opção político-pedagógica emancipatória.

\section{PALAVRAS-CHAVE:}

educação profissional e tecnológica, Paulo Freire, emancipação.

THE FREIREAN DIMENSION IN PROFESSIONAL AND TECHNOLOGICAL EDUCATION: NA INSIGHT ABOUT THESES AND DISSERTATIONS

\begin{abstract}
:
Believing that the Freirean educational perspective is in line with the conception of emancipatory education aimed by the official documents and guidelines of the Federal Institutes, as well as in the search for the development of methodological-theoretical approaches aimed at the achieving of this goal, this research looks to understand how Paulo Freire's works has been used in the context of Professional and Technological Education. For such, it has been made an analysis of the academic production of the area in the CAPES Dissertations and Theses Bank. It was possible to corroborate that the papers that look into the context of the Professional and Technological Education and which use Paulo Freire as theoretical reference do so with coherence, defending a political-pedagogical, emancipatory option.
\end{abstract}

\section{KEYWORDS:}

professional and technological education, Paulo Freire, emancipation. 


\section{INTRODUÇÃO}

Na história educacional brasileira, é recente o emprego da expressão "Educação Profissional e Tecnológica" (EPT) em substituição às expressões "ensino profissionalizante", "ensino profissional" e "formação profissional" para nomear o conjunto das ações educativas formais dedicadas à formação, qualificação e habilitação para o mundo do trabalho. Aprile e Barone (2006) afirmam que, independente da expressão utilizada para nomear as ações direcionadas ao mundo produtivo, tais denominações não surgem por acaso. São expressões historicamente construídas cujo conteúdo não se traduz em termos absolutos e definitivos, mas, sobretudo, na incorporação de dinâmicas socioeconômicas, políticas e culturais que se apresentam diversificadas e mutáveis ao longo de cada momento histórico.

Neste contexto, a Lei n o 11.892/08 instituiu a Rede Federal de Educação Profissional, Científica e Tecnológica, e criou os Institutos Federais de Educação, Ciência e Tecnologia (BRASIL, 2008). Entre os objetivos dos Institutos Federais (IFs) definidos pela lei, um deles é o de estimular e apoiar processos educativos que levem à geração de trabalho e renda e à emancipação do cidadão na perspectiva do desenvolvimento socioeconômico local e regional. Sobre esse objetivo, Silva (2009) comenta que o inciso $V$ traz à luz essa questão de vital importância para a educação profissional e tecnológica, e que o desenvolvimento de processos educativos que levem à geração de trabalho e renda em prol do desenvolvimento local pressupõe uma proposta diferenciada de formação. Formação que conduza o educando à ampliação de sua capacidade de perceber os problemas contemporâneos e posicionar-se criticamente perante estes, ou seja, uma educação emancipatória. Na mesma perspectiva, Pacheco (2011) defende que um dos objetivos basilares dos IFs é derrubar as barreiras entre o ensino técnico e o científico, articulando trabalho, ciência e cultura para a emancipação humana. 
Sob essa ótica, é importante o desenvolvimento de abordagens teóricometodológicas que estejam voltadas à efetivação desse objetivo. Nesse sentido, a leitura e compreensão do mundo em Paulo Freire é a possibilidade de tomar o destino nas próprias mãos, de se construir outro projeto societário por meio da Educação (LAYRARGUES, 2014). É, também, a possibilidade de uma EPT emancipatória.

Para Manfredi (2010), por tudo que Paulo Freire escreve sobre educação crítica, problematizante e progressista, é possível afirmar que, para ele, a educação profissional deve ser entendida como um processo de formação humana, vinculando a formação técnica aos conhecimentos técnicos e científicos na sua historicidade e com a sua função social e política, ou seja, "uma educação voltada para a construção de sujeitos humanos, críticos, social e politicamente ativos" (MANFREDI, 2010, p. 142). Assim, por acreditar que a perspectiva educacional freireana está em sintonia com a concepção de educação pretendida pelos documentos oficiais e diretrizes dos IFs, esta pesquisa busca responder a seguinte questão: como a obra de Paulo Freire vem sendo utilizada no contexto da EPT?

É importante destacar, segundo Saul e Silva (2011; 2012), que a produção bibliográfica sobre e a partir da obra de Paulo Freire cresceu muito nas duas últimas décadas, atestando a atualidade de seu pensamento. Ao redor do mundo, diversas experiências se desenvolvem tomando seu pensamento como referência, o que confere ao conjunto de suas produções o caráter de uma obra universal. Os autores apresentam dados de uma pesquisa realizada pela Cátedra Paulo Freire no Portal da Coordenação de Aperfeiçoamento de Pessoal de Ensino Superior (CAPES), no período de 1987 a 2010. Foram encontrados 1.441 trabalhos utilizando o referencial freireano em diferentes áreas do conhecimento, sendo 1.153 dissertações e 288 teses. Assim, consideram que no mundo acadêmico é crescente o interesse em 
pesquisar seu pensamento tanto para compreendê-lo, como para investigar as múltiplas possibilidades de seu legado para a construção e reconstrução da práxis, na perspectiva crítico-emancipatória (SAUL; SILVA, 2011, 2012).

Por desconhecer como a obra de Paulo Freire e seus fundamentos de educação estão sendo articulados às pesquisas na EPT, objetiva-se, no presente trabalho, identificar a presença de suas ideias nas dissertações e teses em EPT de modo a entender como este referencial teórico está sendo utilizado nestas pesquisas. Para tanto, foi realizada uma análise da produção acadêmica que articulasse os pressupostos freireanos à EPT no Banco de Teses e Dissertações da CAPES. O intuito da pesquisa é contribuir com as discussões da EPT refletindo criticamente sobre o papel que os fundamentos freireanos de educação vêm assumindo nesse contexto.

\section{METODOLOGIA}

A localização das dissertações e teses da área de EPT que usam como referencial teórico a obra de Paulo Freire foi realizada a partir da consulta ao Banco de Teses e Dissertações da CAPES. Os dados foram coletados em março de 2015. Como o Banco de Teses e Dissertações da CAPES passa por uma atualização, no momento da pesquisa só estavam disponíveis os registros das teses e dissertações defendidas em 2011 e 2012. Assim, esta pesquisa, caracterizada como uma revisão integrativa da literatura, é uma pequena amostra deste universo. Inicialmente, utilizando como descritor a expressão exata "educação profissional", foram localizados 516 trabalhos.

A próxima etapa consistiu na leitura dos resumos de todos os trabalhos com a finalidade de selecionar apenas aqueles que, em alguma medida, relacionassem as ideias de Paulo Freire com a EPT. O critério adotado para esta seleção foi apresentar 


\section{DEE Debates

no resumo a citação do autor. Da leitura dos resumos foram selecionados 13 trabalhos, sendo 4 teses e 9 dissertações.

A partir da leitura completa dos trabalhos selecionados foram analisados os focos temáticos das investigações. Foram identificadas as obras citadas, assim como localizados possíveis pressupostos freireanos presentes nas pesquisas. Para verificar se o referencial teórico de Paulo Freire havia sido apropriado nos trabalhos analisados, foram adotados os procedimentos de Zaiuth e Hayashi (2011), que consideraram dois tipos de apropriação: a "citação" para os trabalhos que apenas citam obras de Paulo Freire sem vinculá-las ao referencial teórico adotado, e a "apropriação" em que os autores dos artigos analisados realizam a apropriação do referencial freireano a partir de noções e conceitos do autor para fundamentar a pesquisa.

Os dados mais relevantes foram organizados em tabelas com o objetivo de facilitar a análise das principais tendências nos trabalhos selecionados.

\section{RESULTADOS E DISCUSSÃO}

Dentre os 516 trabalhos selecionados inicialmente, 13 apresentavam em seu resumo citação do autor Paulo Freire. Observa-se no Quadro 1 que a maioria das pesquisas é produzida em nível de mestrado: são 9 dissertações e 4 teses de doutorado. Essa produção está dispersa em uma quantidade considerável de programas de pós-graduação em Educação no Brasil. Apenas 3 trabalhos são pertencentes a programas de outras áreas: pós-graduação em Dança, em Cultura e Sociedade, e outro em Tecnologia e Sociedade. 
Quadro 1: Distribuição dos trabalhos de acordo com o programa de pós-graduação. Fonte:

Dados da Pesquisa.

\begin{tabular}{|c|c|c|c|c|}
\hline \multirow{2}{*}{$\begin{array}{c}\text { ÁREA DE } \\
\text { AVALIAÇÃO }\end{array}$} & PROGRAMA DE PÓS GRADUÇÃO & TESES & DISSERT & \multirow{2}{*}{ TOTAL } \\
\hline \multirow{3}{*}{ Educação } & Educação & 2 & 5 & 7 \\
\cline { 2 - 5 } & Educação Ambiental & 1 & - & 1 \\
\cline { 2 - 5 } & Educação Brasileira & - & 1 & 1 \\
\cline { 2 - 5 } & Educação Conhecimento e Inclusão Social & 1 & - & 1 \\
\hline \multirow{2}{*}{ Interdisciplinar } & Cultura e Sociedade & - & 1 & 1 \\
\cline { 2 - 5 } & Tecnologia e Sociedade & - & 1 & 1 \\
\hline Artes/Música & Dança & 4 & 9 & 1 \\
\hline & TOTAL & & 1 \\
\hline
\end{tabular}

A obra de Paulo Freire compõe-se de livros escritos somente por ele e também em parceria com escritores brasileiros e de outros países. Dos 31 livros publicados no Brasil, 21 foram citados e referenciados nas pesquisas, sendo a obra Pedagogia da Autonomia a mais citada. Esta obra foi referenciada em 11 dos 13 trabalhos analisados, seguida do livro Pedagogia do Oprimido, citado em 7 trabalhos.

Os livros mais citados nos estudos em EPT são destaques na obra de Paulo Freire. Pedagogia do Oprimido (FREIRE, 2014), um de seus principais livros, escrito no período de exílio no Chile, já foi traduzido em mais de vinte idiomas. Streck, Redin e Zitkoski (2010) destacam este livro como uma obra coletiva, e não mais um escrito só de Freire. Seu pensamento pedagógico é um legado que inspira diferentes experiências de educação progressista na perspectiva da emancipação social a partir dos oprimidos. Já Pedagogia da Autonomia foi seu último livro publicado em vida, em 1996. A temática central dessa obra é "a questão da formação docente ao lado da reflexão sobre a prática educativo-progressiva em favor da autonomia do ser dos educandos" (FREIRE, 2004, p. 13). Paulo Freire apresenta os saberes necessários à prática educativa abordando questões fundamentais para a formação de educadores, destacando a responsabilidade ética no exercício da tarefa docente. 
A partir da leitura dos trabalhos foram analisados os focos temáticos de investigação das pesquisas, buscando construir categorias de análise que expressem como a obra de Paulo Freire vem sendo utilizada no contexto da EPT, conforme pode ser visualizado no Quadro 2. De acordo com os dados, o foco das teses e dissertações que usam o referencial freireano é a discussão da relação educador e educando, ponto fundamental na concepção freireana de educação emancipatória. São 5 estudos que têm como foco os educadores, 5 que investigam os saberes e concepções dos educandos, e 3 onde a temática é a organização e os currículos da escola.

Quadro 2: Distribuição dos trabalhos de acordo com o foco temático das investigações. Fonte: dados da pesquisa.

\begin{tabular}{|c|c|c|c|}
\hline $\begin{array}{c}\text { FOCO TEMÁTICO DAS } \\
\text { INVESTIGAÇÕES }\end{array}$ & TESES E DISSERTAÇÕES & TOTAL & $\%$ \\
\hline Educadores & $\begin{array}{c}\text { Auarek (2012); Fortes (2012); Lima (2011); } \\
\text { Carpim (2011); Machado (2011). }\end{array}$ & 5 & 38,5 \\
\hline Educandos & $\begin{array}{c}\text { Bandeira (2011); Berté (2011); Leal (2011); } \\
\text { Lemes (2012); Moro (2012). }\end{array}$ & 5 & 38,5 \\
\hline Escola & Moreno (2012); Nascimento (2012); Zatti (2012). & 3 & 23 \\
\hline TOTAL & 13 & 13 & 100 \\
\hline
\end{tabular}

Nos itens que seguem serão apresentados os trabalhos em suas relações entre Paulo Freire e a EPT.

\subsection{EDUCADORES}

Dos 13 trabalhos analisados, 5 têm como foco de investigação o educador, temática fundamental da obra de Paulo Freire. Forster (2010) comenta que sua principal preocupação é com a formação profissional e com o compromisso sociopolítico desse educador, ser inacabado. O autor tornou-se referência no campo da formação de professores por ser contrário à abordagem tradicional do ensino, denominada por ele de educação bancária. Freire (1997) chama a atenção de quem ousa ensinar para a significação crítica desse ato, assim como a significação crítica de 
aprender. A tarefa de ensinar, para ele, é uma tarefa profissional que exige amorosidade, criatividade, competência científica. É tarefa que recusa a estreiteza cientificista, que exige a capacidade de brigar pela liberdade sem a qual a própria tarefa fenece (FREIRE, 1997). Eis o desafio de Paulo Freire aos educadores.

Entretanto, apesar do tema "formação docente" ser recorrente nas pesquisas do campo da educação, historicamente, as iniciativas de formação de docentes especificamente para a educação profissional no Brasil, segundo Machado (2008), têm se caracterizado pela falta de concepções teóricas consistentes e de políticas públicas amplas e contínuas. Para Oliveira (2010), a formação pedagógica desse professor vem sendo tratada no país como algo especial, emergencial, sem integralidade própria, e viabilizando propostas de formação aligeirada e superficial, que carece de marco regulatório. Urbanetz (2012), em um estudo da produção acadêmica sobre formação de professores para a educação profissional, observa a quase inexistência dessa temática em pesquisas e publicações. Para a autora, isso se dá a partir da indefinição de políticas de formação para esses docentes, ainda que esse seja um tema de análise urgente diante da importância que a educação profissional tem no cenário nacional.

Sob essa ótica, em sua pesquisa, Auarek (2012) busca compreender como é composta a qualidade das relações de cooperação entre um professor da EPT e seus alunos em um laboratório de ensino, e as influências dessa relação para a atividade de trabalho docente. Os dados principais que embasaram a análise foram originários de observações, registros de áudio e filmagens de aulas realizadas no laboratório da disciplina de Comandos Elétricos de um curso técnico de eletrotécnica de nível médio, além de uma entrevista em profundidade com o professor da disciplina. $\mathrm{Na}$ tese, ocorre a apropriação do referencial freireano. Freire foi o eixo de apoio da autora para o desenvolvimento da análise do trabalho do professor baseada nos 
saberes necessários à prática educativa. Por exemplo, ao analisar as aulas de laboratório e a manifestação de imprevistos que surpreendem professor e aluno, Auarek (2012) observa que:

A confrontação frequente com o imprevisto parece fazer circular os valores de que não existe quem de antemão sabe tudo. Tudo pode estar por acontecer, tudo é falível, tudo é passível de ser construído, desde que se respeite o que não se conhece e quem não conhece. Pensa-se que o imprevisto explicita aluno e professor como seres inacabados e thes clarifica a consciência de se verem como inacabados (AUAREK, 2012, p. 146).

Compreender através das trajetórias de vida de 6 professores da EPT OS processos constitutivos da docência é o foco da pesquisa de Fortes (2012). É uma pesquisa qualitativa com inspiração nos princípios da etnografia e que utiliza como estratégias principais a análise documental, as observações e as entrevistas narrativas, as quais constituíram o modo de apreensão e análise. A autora faz a interlocução e apropriação do referencial freireano ao analisar os dados das narrativas de vida dos professores, como demostra o texto a seguir:

Dentre as articulações da vida já apresentadas, que levam engenheiros e bacharéis da Ciência da Computação a se aproximarem da docência, percebe-se que elas se configuram em dimensões distintas, no entanto, articuladas entre si, no que se refere ao prazer de aprender um "jeito de ser professor" à medida que ensinam o que aprenderam nas vivências acadêmicas. Nesse sentido, é possível inferir que a concepção freireana se faz presente, já que o professor só ensina verdadeiramente, na medida em que conhece o conteúdo que ensina, quer dizer, na medida em que se aproxima dele, em que o aprende (FORTES, 2012, p. 174).

A pesquisadora chama a atenção para que nos processos de formação docente na EPT, os professores e as professoras sejam vistos como sujeitos sociais e, como tais, sujeitos de seus processos formativos, considerando as relações que estabelecem consigo e com o mundo (FORTES, 2012). 


\section{D|EDebates

Lima (2011) desenvolveu uma pesquisa sobre formação de formadores no âmbito do Programa Nacional de Integração da Educação Profissional com a Educação Básica na Modalidade de Educação de Jovens e Adultos (PROEJA). O estudo foi desenvolvido com 8 professores da EPT formadores em formação que se reuniam semanalmente para planejar e executar um curso de formação continuada: Encontros Dialógicos com o PROEJA. Essa atividade aconteceu como uma "Roda de Formação" entendida enquanto um espaço coletivo e colaborativo concebido como uma reinvenção dos Círculos de Cultura freireano. A apropriação do referencial teórico de Paulo Freire perpassou toda a pesquisa que foi orientada pelo pressuposto da concepção freireana do homem e da mulher como seres inconclusos. Portanto, em processo de construção:

A proposta de formação permanente defendida fundamentou-se na perspectiva freireana da inconclusão e da incompletude, que ao entender o ser humano como inconcluso e que se faz à medida que existe, ou como escreve muitas vezes "está sendo", aponta para a necessidade de processos de formação permanente (LIMA, 2011, p. 15).

Carpim (2011), realizou uma pesquisa com 33 professores da EPT. Destes, 10 mostraram-se dispostos e foram convidados a participar de um curso de educação continuada, sendo um módulo presencial e outro à distância sobre a docência na educação profissional num paradigma da complexidade. A autora apresenta os aspectos das práticas pedagógicas tradicional e inovadora e da formação de professores baseada em vários autores, sendo um deles Freire. Pode-se considerar que o trabalho não teve a apropriação do referencial freireano. O autor foi citado algumas vezes, mas é contraditório, já que a formação proposta não tem a perspectiva freireana de formação permanente com a demanda e autonomia dos professores. 
Já Machado (2011) analisou a forma como instituições de ensino superior e de EPT construíram um processo de formação de professores conteudistas para a produção do material didático impresso do Sistema e-Tec Brasil à luz dos referenciais para elaboração de material didático para Educação à Distância (EaD). Apesar da menção a Freire no resumo como um dos referenciais teóricos do trabalho, o autor é citado apenas uma vez. Não ocorre a apropriação do referencial freireano, somente são apresentados os saberes necessários à prática educativa quando a autora discute os pressupostos para a formação docente em EaD.

Assim, observa-se nas pesquisas com foco no educador que, apesar de existirem ainda poucas iniciativas de formação docente especificamente para a EPT no Brasil, existe uma busca por paradigmas que superem abordagens técnicas e positivistas da produção do conhecimento. A maioria dos estudos apresenta modelos críticos de formação docente numa perspectiva problematizadora, se apropriando com coerência do referencial teórico freireano. Nos modelos construídos no cerne de uma racionalidade crítica, segundo Saul e Saul (2016), a práxis assume um papel central no desvelamento da realidade. No modelo crítico, a ênfase na visão política na prática educativa caracteriza o professor como alguém que levanta problemas e dirige um diálogo crítico em sala de aula, na busca de mudanças e transformações em si e nas estruturas sociais que condicionam a educação (ARAUJO, 2009).

Para Freire (2004), ensinar exige consciência do inacabamento, da inconclusão do ser humano e esse foi o pressuposto freireano mais frequente nas pesquisas com foco no educador. Essa ideia freireana de que o ser humano é um ser inacabado e de infinitas possibilidades é o que torna a educação possível para estes pesquisadores. 


\subsection{EDUCANDOS}

Cinco estudos tiveram como foco temático os educandos. Paulo Freire criticou a concepção bancária de educação, em que o educador é sujeito do processo e o educando apenas objeto. Ao posicionar o educando como um sujeito do processo através do diálogo, Freire dá voz aos educandos. Para ele não há docência sem discência, e seus sujeitos, apesar de suas diferenças, não se reduzem à condição de objeto um do outro. Sob essa ótica, o diálogo é uma estratégia para respeitar o saber do aluno que chega à escola e também tem o que dizer e não apenas o que escutar.

Nesse sentido, Bandeira (2011) investigou as concepções e práticas de leitura desenvolvidas por 6 estudantes de um curso PROEJA, a fim de traçar o perfil de leitor de cada um dos sujeitos da pesquisa. Memoriais de leitura foram produzidos a partir de entrevistas gravadas com os educandos. Ao contextualizar o PROEJA, a autora faz um histórico da Educação de Jovens e Adultos (EJA) no Brasil e traz Paulo Freire como o grande pensador desta modalidade de ensino. A apropriação do referencial teórico freireano aparece na pesquisa. Bandeira (2011) assume a EJA na perspectiva libertadora, humanizadora e crítica, pelo viés da Educação Popular. Freire foi um dos referenciais da autora no processo para o entendimento da leitura e escrita dos alunos:

A leitura deve ser tomada como um processo que acontece desde os primeiros contatos do homem com o mundo, bem antes de este chegar à escola, uma vez que faz parte da própria condição humana procurar dar sentido ao que e a quem nos cerca. Isso é confirmado por Freire (1999, p. 11), quando afirma que "a leitura do mundo precede a leitura da palavra e a leitura desta implica a continuidade da leitura daquela". As descobertas vão sendo feitas através da leitura daquilo que se vê, sente ou do que se tem ao redor (BANDEIRA, 2011, p. 41). 
Em sua dissertação, Berté (2011) desenvolve uma pesquisa artístico-científica que tem como objetivo propor relações entre corpo, imagem e pergunta, considerando a experiência e a indissociabilidade entre teoria e prática, para articular entrecruzamentos entre processos criativos e pedagógicos em dança. No estudo, o autor busca questionar o entendimento tradicional de História da Dança como uma disciplina teórica na qual não se dança e não se usa o corpo. A pesquisa se dá com uma experiência artístico-pedagógica realizada pelo autor, enquanto educador e coreógrafo, junto a 20 educandos de uma turma de curso técnico em dança. Verifica-se a apropriação do referencial teórico freireano ao longo do estudo nas conexões entre dança e educação que, para o autor, são realizadas através da pedagogia da pergunta de Freire e Faundez, com a qual mais do que dar respostas se ensina a perguntar:

Os autores identificam a pergunta atrelada ao cotidiano, aqui entendido em relação ao ambiente com o qual o corpo se relaciona. Se toda experiência humana só se dá com corpo, seja ela compreendida como mais abstrata ou mais concreta, a pergunta, como ação contida nesse conjunto de experiências, só pode ser pergunta do corpo, com corpo, no corpo. Desse modo, as perguntas acerca do conhecimento, da vida, da existência, ou, o perguntar-se acerca disso, implica compreender a corponectividade. Conhecer, na sua vasta gama de possibilidades, é uma ação complexamente atrelada aos procedimentos e perguntas que o corpo faz (BERTÉ, 2011, p. 127).

Leal (2011) busca, em sua pesquisa, compreender como se dá o processo de ressocialização discente no PROEJA, através de entrevistas em profundidade com 9 alunos. A apropriação do referencial no trabalho se dá pela adoção da concepção freireana de Educação Popular. A autora caracteriza a prática pedagógica do programa e identifica sua interferência no processo de ressocialização discente baseada na perspectiva freireana da inconclusão do ser humano: 
Ressocializar não significa o trabalho dos que sabem, sentem e agem sobre os que ainda não conseguem fazê-lo, ou, ainda, a adaptação dos inadaptados socialmente. Não é isso. O caráter da ressocialização, segundo Souza (2007) e Freire (2007), está na natureza do ser humano como um ser de relação e inconcluso. Assim, constantemente, está aprendendo a pensar, a sentir, a fazer, a ser, individual e coletivamente (LEAL, 2011, p. 81).

Lemes (2012) investigou as significações e indicações de estudantes egressos de um curso do PROEJA, através de entrevistas individuais e coletivas, para a construção de um itinerário formativo entre EJA e EP. A autora declara que a escolha por dar voz aos estudantes revela sua opção político-pedagógica baseada na perspectiva freireana de educação. A apropriação do referencial freireano perpassa todas as análises e reflexões da pesquisadora. Segundo a autora, o próprio Projeto PROEJA pesquisado tem entre seus princípios básicos o diálogo e a construção coletiva do conhecimento:

\begin{abstract}
Com base nas entrevistas e nas observações registradas no Diário de Itinerância, levanto indícios de que a Oficina Transiarte-CEM03 parece ser um espaço que oportuniza a vez, a voz e a decisão dos sujeitos. Uma relação educativa que se propõe a "fazer com" e não "para" os sujeitos, como pontua Freire (2005) (LEMES, 2012, p. 163).
\end{abstract}

Em seu trabalho, Moro (2012) procurou identificar e estabelecer as relações entre os saberes que os estudantes adquirem no trabalho, de natureza prática e tácita, e os saberes de cunho científico e teórico, principalmente os de Física, aos quais tiveram acesso na escola. Participaram da pesquisa 13 alunos e 5 professores de um curso do PROEJA. Moro (2012) apresenta o trabalho como categoria central e como princípio educativo apoiado, dentre outros, nos trabalhos de Paulo Freire, enfatizando, no referencial teórico, os fundamentos ontológicos e as formas de acesso ao conhecimento por parte dos trabalhadores. As ações pedagógicas de 
Freire são, na concepção do autor, projetos que tomam o trabalho humano como fundamento para a formação do sujeito omnilateral, integral e consciente:

Para Freire (2007), conduzido pelos seus ideais libertadores de ensino, a escolha dos temas da educação do trabalhador é uma escolha democrática, derivada de um processo gradual, mediado pela relação dos educandos com o mundo e deles com seus próprios educadores: “(...) o conteúdo programático para a ação, que é de ambos, não possa ser de exclusiva eleição daqueles, mas, deles e do povo (MORO, 2012, p. 40).

Das 5 pesquisas com foco temático nos educandos, 4 são estudos que envolvem o PROEJA. Esta modalidade de ensino é um desafio enfrentado atualmente pela EPT, visto que constitui uma nova forma de pensar a Educação de Jovens e Adultos, por integrar formação geral e educação profissional, com vista a uma educação básica e profissional sólida e à formação integral do educando (BRASIL, 2006). Não é uma surpresa que Paulo Freire seja a principal referência teórica desses trabalhos, já que o próprio documento base do PROEJA traz em sua concepção um olhar freireano para os educandos:

Os sujeitos alunos deste processo não terão garantia de emprego ou melhoria material de vida, mas abrirão possibilidades de alcançar esses objetivos, além de se enriquecerem com outras referências culturais, sociais, históricas, laborais, ou seja, terão a possibilidade de ler o mundo, no sentido freireano, estando no mundo e o compreendendo de forma diferente da anterior ao processo formativo (BRASIL, 2007, p. 36).

Os trabalhos analisados apresentam uma perspectiva emancipatória da educação de adultos, intimamente ligada à obra de Paulo Freire. A leitura de mundo foi o principal pressuposto freireano encontrado nessas pesquisas. Passos (2010) destaca que a leitura do mundo e da palavra é, em Freire, direito subjetivo, pois dominando signos e sentidos nos humanizamos, acessando mediações de poder e cidadania. E é sob essa ótica que os pesquisadores realizaram seus estudos. 


\subsection{ESCOLA}

Paulo Freire sempre destacou que não é só na escola que se aprende, mas que esse é um lugar de luta e esperança. Foi defensor da escola pública popular como espaço de resgate científico de cultura popular, como espaço de organização política das classes populares e instrumento de luta contra-hegemônica (GADOTTI, 2010). Na concepção freireana, segundo Saul e Silva (2011), a escola democrática tem como princípios inerentes, a participação e a autonomia, e isso significa admitir que todos os sujeitos envolvidos com a escola têm o direito de tomar decisões. Freire, em uma de suas falas como Secretário da Educação do Município de São Paulo, defende esses princípios:

[...] Acreditamos que nosso povo faz juz [sic] ao lugar que é dele, por direito; como decorrência, acreditamos que nossos meninos(as) da rede municipal escolar são capazes e competentes de gerenciar (conosco) o aprendizado deles(as); e acreditamos em nossos(as) professores(as) como sujeitos de ações pedagógicas que eles(as) constroem (NOGUEIRA; GERALDI, 1990, p. 54).

Nesse contexto, três estudos tiveram como foco de investigação a escola. Um deles questiona um modelo institucional de educação e dois buscam entender a efetivação e o desenvolvimento de currículos escolares.

O foco central da tese de Zatti (2012) é a problematização e análise das possibilidades emancipatórias do modelo de educação técnico-científica implantado como EPT nos Institutos Federais (IFs). A apropriação do referencial freireano se deu ao longo de todo trabalho. A concepção de educação técnico-científica emancipatória adotada para a análise foi elaborada pelo autor a partir dos conceitos de racionalidade dialógica de Freire e racionalidade comunicativa de Habermas. Ao analisar a documentação que criou e regulamentou os IFs defende que: 
[...] A emancipação é citada, na lei acima, em relação com a cidadania e, esta, ao desenvolvimento socioeconômico local e regional. Portanto, emancipação está definida como relacionada à transformação da realidade na qual essas instituições inserem-se, o que está de acordo com a concepção de educação emancipatória de Paulo Freire (ZATTI, 2012, p. 147).

Zatti (2012) afirma que a análise documental e as entrevistas com professores indicam que a EPT em implantação nos IFs possui como marca inovadora a perspectiva de construção de uma educação emancipatória, o que está ocorrendo, apesar de algumas contradições e dificuldades que foram levantadas na pesquisa.

Moreno (2012) buscou compreender em sua dissertação se as múltiplas identidades dos sujeitos que compõem o público de um curso do PROEJA estão sendo consideradas, atentando-se para as conexões entre práticas educacionais, representações culturais e sociais na efetivação do currículo escolar. A autora entende que, para que o PROEJA concretize os seus objetivos, é essencial a elaboração e efetivação de currículos que envolvam as identidades dos educandos da EJA. Ela se apropriou do referencial freireano para discutir a EJA no Brasil e trouxe as contribuições de Paulo Freire para as teorias críticas do currículo.

O papel importante que Paulo Freire atribui ao vínculo entre educação e cultura ao destacar a relevância do currículo escolar tem como matriz os conhecimentos prévios dos educandos, baseando-se no contexto social, cultural, familiar e laboral desses, para o planejamento e efetivação das práticas curriculares, possibilitando, desta forma um processo de ensinoaprendizagem verdadeiramente significativo, o que contribuiu, notoriamente, para as teorias críticas do currículo (MORENO, 2012, p. 56).

Nascimento (2012) objetiva, em seu trabalho, analisar a relação entre tempo e espaço no desenvolvimento do currículo prescrito e em ação de um curso do PROEJA. Para tanto, analisou documentos oficiais acerca da temática, aplicou questionários com alunos e professores e realizou um grupo focal. A apropriação de 
Freire aparece na fundamentação da pesquisa. Apresenta a história da EJA no Brasil e sua relação com Paulo Freire. O referencial freireano aparece também na análise e interpretação dos dados:

Observamos que se tratando da relação pedagógica professor-aluno, normalmente determinada pela escola e pela prática docente, que está muito centrada no desenvolvimento do currículo e não ocorre de uma forma dialogada, que deveria ser pautada em uma relação intersubjetiva, com destaque para a reflexão dialogada fundada no pensamento sóciopedagógico de Freire (1983), por meio do método de conscientização (NASCIMENTO, 2012, p. 32).

É importante destacar que os estudos analisados buscaram formas de problematizar a escola, com as análises críticas sobre as propostas e práticas curriculares e sobre as expectativas por parte dos integrantes da escola se apropriando com coerência do referencial teórico freireano. A possibilidade de uma educação emancipatória para a EPT foi o principal pressuposto freireano discutido nessas pesquisas.

\section{CONCLUSÃO OU CONSIDERAÇÕES FINAIS}

Paulo Freire, reconhecido internacionalmente e nomeado Patrono da Educação Brasileira (BRASIL, 2012), apresenta em sua obra a construção do conhecimento como algo coletivo, onde todos estão envolvidos, mostrando que não há um sujeito que ensina e um que aprende, todos estão em permanente aprendizagem.

Pode-se afirmar que as ideias de Paulo Freire vêm se fazendo presentes nas teses e dissertações que investigam o contexto da EPT. As duas obras mais referenciadas pelos pesquisadores foram Pedagogia da Autonomia e Pedagogia do Oprimido. Essas pesquisas, em sua maioria, apresentam modelos críticos de formação de educadores-educandos e educandos-educadores numa perspectiva 
problematizadora. Com a leitura dos trabalhos, foi possível verificar também que grande parte deles têm como foco específico o ambiente do PROEJA, seja investigando a formação de seus educadores, de seus educandos, ou sua organização curricular.

Os dados do levantamento realizado, mesmo que parciais, permitem inferir que, predominantemente, os trabalhos que investigam o contexto da EPT e que utilizam Paulo Freire como referencial teórico o fazem com coerência, defendendo uma opção político-pedagógica emancipatória, como pretendem os documentos e diretrizes dos IFs. Observa-se nas pesquisas a busca por uma EPT que rompa com a formação de profissionais simplesmente adaptados ao mercado de trabalho, e que promova uma formação crítica, emancipadora e fomentadora de uma realidade mais digna e mais justa.

\section{REFERÊNCIAS}

APRILE, Maria Rita; BARONE, Rosa Elisa Mirra. Educação Profissional no Brasil e opções metodológicas de pesquisa: elementos para o debate. Boletim Técnico do SENAC, Rio de Janeiro, v. 32, n. 1, p.56-67, jan. 2006. Disponível em:

<http://www.senac.br/BTS/321/bts32_1-artigo4.pdf>. Acesso em: 05 abr. 2016.

ARAUJO, Marlinda Pessôa. Formação Docente: caminhos percorridos em busca de um processo colaborativo. In: ENCONTRO DE PESQUISA EM EDUCAÇÃO DA UFPI, 5., 2009, Teresina. Anais... Teresina: IFPI, 2009. p. 1 - 13. Disponível em: <http://leg.ufpi.br/subsiteFiles/ppged/arquivos/files/eventos/evento2009/GT.2/36_ Marlinda Pessoa Araujo.pdf>. Acesso em: 15 out. 2015.

AUAREK, Wanilde Mary Ferrari. Educação Profissional Técnica de nível médio: Circulação de saberes e valores na atividade de trabalho. 2012. 266 f. Tese (Doutorado) - Curso de Pós-graduação em Educação Conhecimento e Inclusão Social, 


\section{D|EDebates

Faculdade de Educação, Universidade Federal de Minas Gerais, Belo Horizonte, 2012.

BANDEIRA, Francisca Vera Célida Feitosa. Concepções e práticas de leitura na Educação de Jovens e Adultos: o que revelam os memoriais de estudantes do Instituto Federal da Paraíba - Campus de Cajazeiras. 2011. 93 f. Dissertação (Mestrado) Curso de Pós-graduação em Educação, Centro de Educação, Universidade Federal da Paraíba, João Pessoa, 2011.

BERTÉ, Odailso Sinvaldo. Filosofazendo dança com Pina Bausch: bricolagem entre experiência, imagens e conceitos em processos criativos e pedagógicos. 2011. 172 f. Dissertação (Mestrado) - Curso de Pós-graduação em Dança, Escola de Dança, Universidade Federal da Bahia, Salvador, 2011.

BRASIL. Decreto no 5.840, de 13 de julho de 2006. Institui, no âmbito federal, o Programa Nacional de Integração da Educação Profissional com a Educação Básica na Modalidade de Educação de Jovens e Adultos - PROEJA, e dá outras providências.. Decreto № 5.840/2006.. Disponível em:

<https://www.planalto.gov.br/ccivil_03/_Ato2004-2006/2006/Decreto/D5840.htm>. Acesso em: 26 jul. 2014.

BRASIL. Institui a Rede Federal de Educação Profissional, Científica e Tecnológica, cria os Institutos Federais de Educação, Ciência e Tecnologia, e dá outras providências. Lei 11.892/2008. Brasília, DF, Disponível em:

<http://www.planalto.gov.br/ccivil_03/_Ato2007-2010/2008/Lei/L11892.htm>. Acesso em: 25 nov. 2015.

BRASIL Lei no 12.612, de 13 de abril de 2012. Declara o educador Paulo Freire Patrono da Educação Brasileira. Lei 12.612/2012. Disponível em: 
<http://www.planalto.gov.br/ccivil_03/_Ato2011-2014/2012/Lei/L12612.htm>. Acesso em: 12 maio 2016.

BRASIL. Ministério da Educação. Secretaria de Educação Profissional e Tecnológica. Programa Nacional de Integração da Educação Profissional com a educação Básica na Modalidade de Educação de Jovens e Adultos - PROEJA: Documento Base. Brasília: SETEC, 2007. 74 p. Disponível em: <http://portal.mec.gov.br/setec/arquivos/pdf2/proeja_medio.pdf>. Acesso em: 25 nov. 2014.

CARPIM, Lucymara. Formação pedagógica dos professores do ensino técnico: caminhos históricos para um paradigma da complexidade. 2011. 173 f. Dissertação (Mestrado) - Curso de Pós-graduação Stricto Sensu - Mestrado em Educação, Pontifícia Universidade Católica do Paraná, Curitiba, 2011.

FORSTER, Mari Margarete dos Santos. Educador/educando. In: STRECK, Danilo R.; REDIN, Euclides; ZITKOSKI, Jaime José (Org.). Dicionário Paulo Freire. 2. ed. Belo Horizonte: Autêntica, 2010. p. 143-145.

FORTES, Maria Carolina. Entrelaçamentos de Vidas: a constituição da Docência na Educação Profissional e Tecnológica. 2012. 263 f. Tese (Doutorado) - Curso de Pósgraduação em Educação, Faculdade de Educação, Pontifícia Universidade Católica do Rio Grande do Sul, Porto Alegre, 2012.

FREIRE, Paulo. Professora sim, tia não: cartas a quem ousa ensinar. São Paulo: Olho D’Água, 1997. 84 p. Disponível em:

<http://www.paulofreire.ufpb.br/paulofreire/Files/livros_obra/paulo_freire_profess ora_sim_tia_nao.pdf $>$. Acesso em: 29 set. 2015

FREIRE, Paulo. Pedagogia da autonomia: saberes necessários à prática educativa. 29. ed. São Paulo: Paz e Terra, 2004. 148 p. 


\section{D|EDebates

FREIRE, Paulo. Pedagogia do Oprimido. 57. ed. Rio de Janeiro: Paz e Terra, 2014. 253 p.

GADOTTI, Moacir. Escola. In: STRECK, Danilo R.; REDIN, Euclides; ZITKOSKI, Jaime José (Org.). Dicionário Paulo Freire. 2. ed. Belo Horizonte: Autêntica, 2010. p. 154-156.

LAYRARGUES, Philippe Pomier. Prefácio: A dimensão freireana na Educação Ambiental. In: LOUREIRO, Frederico Bernando; TORRES, Juliana Rezende (Org.). Educação Ambiental: dialogando com Paulo Freire. São Paulo: Cortez, 2014. p. 7-12.

LEAL, Norma de Morais. O processo de ressocialização do sujeito discente no Programa Nacional de Integração da Educação Profissional com a Educação Básica na modalidade de Educação de Jovens e Adultos - PROEJA. 2011. 187 f. Dissertação (Mestrado) - Curso de Programa de Pós-graduação em Educação, Universidade Federal de Pernambuco, Recife, 2011.

LEMES, Julieta Borges. O PROEJA TRANSIARTE na Educação de Jovens e Adultos do Centro de ensino médio 03 e na Educação Profissional do Centro de Educação Profissional de Ceilândia: significações e indicações de estudantes à elaboração de um itinerário formativo. 2012. 265 f. Dissertação (Mestrado) - Curso de Pósgraduação em Educação, Faculdade de Educação, Universidade de Brasília, Brasília, 2012.

LIMA, Cleiva Aguiar de. O diário em roda, roda em movimento: formar-se ao formar professores no Proeja. 2011. 188 f. Tese (Doutorado) - Curso de Pós-graduação em Educação Ambiental, Universidade Federal de Rio Grande, Rio Grande, 2011. MACHADO, Lucília Regina de Souza. Diferenciais inovadores na formação de professores para a educação profissional. Revista Brasileira da Educação Profissional e Tecnológica, Brasília, v. 1, n. 1, p.8-22, jun. 2008. Disponível em: 
<http://portal.mec.gov.br/setec/arquivos/pdf3/rev_brasileira.pdf>. Acesso em: 05 nov. 2014.

MACHADO, Mércia Freire Rocha Cordeiro. A formação do professor para a produção de material didático impresso em EAD. 2011. 170 f. Dissertação (Mestrado) - Curso de Pós-graduação em Educação, Centro de Teologia e Ciências Humanas, Pontifícia Universidade Católica do Paraná, Curitiba, 2011.

MANFREDI, Silvia Maria. Educação Profissional. In: STRECK, Danilo R.; REDIN, Euclides; ZITKOSKI, Jaime José (Org.). Dicionário Paulo Freire. 2. ed. Belo Horizonte: Autêntica, 2010. p. 141-142.

MORENO, Sandra Antonielle Garcês. PROEJA: entre currículos e identidades. 2012. 161 f. Dissertação (Mestrado) - Curso de Pós-graduação em Cultura e Sociedade, Universidade Federal do Maranhão, São Luís, 2012.

MORO, Guilherme Andre Dal. Do trabalho para a escola: olhares de trabalhadoresestudantes e professores sobre as relações entre o saber da prática e o saber da escola. 2012. 176 f. Dissertação (Mestrado) - Curso de Pós-graduação em Tecnologia, Universidade Tecnológica Federal do Paraná, Curitiba, 2012.

NASCIMENTO, Marilene Ferreira do. A organização do tempo e espaço na proposta curricular no curso de edificações do IFPA. 2012. 121 f. Dissertação (Mestrado) Curso de Pós-graduação em Educação Brasileira, Faculdade de Educação, Universidade Federal do Ceará, Fortaleza, 2012.

NOGUEIRA, Adriano; GERALDI, João Wanderley (Org.). Paulo Freire: trabalho, comentário, reflexão. Petrópolis: Vozes, 1990. 86 p.

OLIVEIRA, Maria Rita Neto Sales. A formação de professores para a Educação Profissional. In: DALBEN, Ângela Imaculada Loureiro de Freitas et al (Org.). 


\section{D|EDebates

Convergências e tensões no campo da formação e do trabalho docente. 3. ed. Belo Horizonte: Autêntica, 2010. Cap. 3. p. 454-478.

PACHECO, Eliezer. Institutos federais: uma revolução na educação profissional e tecnológica. In: PACHECO, Eliezer (Org.). Institutos federais: uma revolução na educação profissional e tecnológica. São Paulo: Moderna, 2011. p. 13-32.

PASSOS, Luiz Augusto. Leitura do mundo. In: STRECK, Danilo R.; REDIN, Euclides; ZITKOSKI, Jaime José (Org.). Dicionário Paulo Freire. 2. ed. Belo Horizonte: Autêntica, 2010. p. 238-240.

SAUL, Ana Maria; SAUL, Alexandre. Contribuições de Paulo Freire para a formação de educadores: fundamentos e práticas de um paradigma contra-hegemônico. Educar em Revista. Curitiba, n. 61, p.19-35, set. 2016. Disponível em:

<http://revistas.ufpr.br/educar>. Acesso em: 20 set. 2016.

SAUL, Ana Maria; SILVA, Antonio Fernando Gouvêa. O pensamento de Paulo Freire no campo de forças das políticas de currículo: a democratização da escola. Revista Ecurriculum, São Paulo, v. 7, n. 3, p.1-24, dez. 2011. Disponível em:

<http://revistas.pucsp.br/index.php/curriculum/article/view/7597/5547>. Acesso em: 14 maio 2015.

SAUL, Ana Maria; SILVA, Antonio Fernando Gouvêa. O pensamento de Paulo Freire em sistemas públicos de ensino: pesquisando políticas de currículo em um mesmo território sob olhares diferentes. Revista Teias, Rio de Janeiro, v. 13, n. 27, p.9-26, abr. 2012. Disponível em:

<http://www.periodicos.proped.pro.br/index.php/revistateias/article/viewFile/1137/ 821>. Acesso em: 01 abr. 2015.

SILVA, Caetana Juracy Resende (Org.). Institutos Federais lei 11.892, de 29/11/2008: comentários e reflexões. Brasília: IFRN, 2009. 70 p. 
STRECK, Danilo R.; REDIN, Euclides; ZITKOSKI, Jaime José. Paulo Freire: uma breve cartografia intelectual. In: STRECK, Danilo R.; REDIN, Euclides; ZITKOSKI, Jaime José. Dicionário Paulo Freire. 2. ed. Belo Horizonte: Autêntica, 2010. p. 15-22.

URBANETZ, Sandra Terezinha. Uma ilustre desconhecida: a formação docente para a educação profissional. Revista Diálogo Educacional, Curitiba, v. 12, n. 37, p.863-883, set. 2012. Disponível em:

$<$ http://www2.pucpr.br/reol/pb/index.php/dialogo?dd1=7207\&dd99=view\&dd98=p b>. Acesso em: 10 nov. 2015.

ZAIUTH, Gabriela; HAYASHI, Maria Cristina Piumbato Innocentini. Apropriação do referencial teórico de Paulo Freire nos estudos sobre educação CTS. Revista Brasileira de Ciência, Tecnologia e Sociedade, São Carlos, v. 2, n. 1, p.278-292, jan. 2011. Disponível em:

<http://www.revistabrasileiradects.ufscar.br/index.php/cts/article/viewFile/129/73>. Acesso em: 25 jun. 2015.

ZATTI, Vicente. Educação técnico-científica emancipatória nos IFETs: um olhar através de Habermas e Freire. 2012. 211 f. Tese (Doutorado) - Curso de Pósgraduação em Educação, Faculdade de Educação, Universidade Federal do Rio Grande do Sul, Porto Alegre, 2012.

Recebido em: Outubro de 2017. Publicado em: Dezembro de 2017. 